\title{
Composição química e rendimento da carne ovina in natura e assada
}

\author{
Chemical composition and yield of in natura and roast sheep meat
}

\author{
Rafael Silvio Bonilha PINHEIRO ${ }^{1 \star}$, André Mendes JORGE ${ }^{1}$, \\ Caroline de Lima FRANCISCO ${ }^{1}$, Ernani Nery de ANDRADE ${ }^{1}$
}

\section{Resumo}

Utilizou-se o músculo Triceps brachii de cordeiros não castrados $1 \frac{1}{2}$ Ile de France $1 \frac{1}{2}$ Santa Inês terminados em confinamento para a realização das análises físico-químicas. Foram determinados: a umidade, a proteína, a gordura, as cinzas e os carboidratos da carne, in natura e assada, destes animais, assim como o rendimento desta carne, após o processo de cocção. A carne assada apresentou valores maiores de gordura e proteína (7,49 e 33,67\%) em comparação com a carne in natura (5,36 e 18,85\%), respectivamente. Os percentuais de cinzas e carboidratos não foram influenciados pelos tratamentos estudados, porém para os valores de umidade, a carne in natura obteve valores superiores ao da carne assada, 74,05 e 57,02\%, respectivamente. A carne assada teve perdas durante o seu preparo por evaporação, por gotejamento e por cocção de 33,20, 1,36 e 35,20\%, respectivamente. Concluiu-se que a carne assada apresenta valor nutricional mais elevado que a carne in natura, para os teores de gordura e proteína, pelo fato da carne in natura apresentar maior valor de umidade em relação à assada, ocasionando assim a concentração de gordura e de proteína na carne assada. O preparo da carne ocasionou perdas por cocção de $35,20 \%$, por gotejamento e evaporação.

Palavras-chave: cocção da carne; cordeiro; composição centesimal; consumidor.

\begin{abstract}
Tríceps brachii muscle from non-castrated $1 / 2$ Ile de France $1 \frac{1}{2}$ Santa Inês lambs terminated in confinement was used for physical and chemical analyses. In natura and roast meat moisture, protein, fat, ashes, carbohydrates, and meat yield were determined after the cooking process. Roast meat presented higher fat and protein values (7,49 and 33,67\%), compared to in natura meat (5,36 and 18,85\%), respectively. Ashes and carbohydrates percentages were not influenced by the treatments studied; however, in natura meat presented higher moisture values than roast meat (74,05 and 57,02\%, respectively). Roast meat presented losses of 33, 20, 1,36, and 35,20\% from evaporation, dripping, and cooking during its preparation, respectively. We concluded that roast meat presents higher nutritional value than in natura meat for fat and protein contents because in natura meat presents higher moisture value than roast meat, so roast meat presents higher fat and protein concentration. Meat preparation resulted in cooking losses of 35,20\% from dripping and evaporation.
\end{abstract}

Keywords: centesimal composition; consumer; lamb; meat cooking.

\section{Introdução}

A ovinocultura de corte no Brasil está em franca expansão, em virtude do aumento do consumo da carne desta espécie animal e também pela oferta de carne ser menor que a demanda do mercado interno, o que causa a valorização do produto. Isso torna a criação destes animais economicamente mais rentável em relação às demais espécies produtoras de carne para consumo humano.

Grande parte das carnes e de produtos cárneos consumidos atualmente pelo homem passa por algum tipo de tratamento térmico, por ser mais palatável e também por eliminar ou diminuir a contaminação microbiana; tal processo pode alterar a qualidade do produto in natura, sendo importante conhecer a composição de alimentos cárneos assados. O processo térmico empregado na preparação dos alimentos altera o rendimento do produto final, sendo oportuno conhecer a alteração deste rendimento.
Os produtos prontos para consumo, incluindo os produtos cárneos, constituem excelente alternativa para o mercado (SILVA, 2004). Para os locais que comercializam produtos cárneos prontos, é uma forma de agregar valor à matéria-prima. Para o consumidor, a aquisição dos produtos prontos se faz oportuna, diante da necessidade crescente de minimizar o tempo de preparo dos alimentos, principalmente para as pessoas dos grandes centros urbanos.

A cocção dos alimentos proporciona trocas físicas, químicas e estruturais de seus componentes pelo efeito do calor (ROSA et al., 2006). As formas de transferência de calor, a temperatura, a duração do processo, e o meio de cocção para o preparo da carne são alguns dos fatores responsáveis pelas alterações químicas e físicas que podem modificar a composição química e o valor nutricional da mesma (GARCIA-ARIAS et al., 2003).

Recebido para publicação em 17/5/2007

Aceito para publicação em 20/3/2008 (002533)

${ }^{1}$ Departamento de Produção Animal, Faculdade de Medicina Veterinária e Zootecnia - FMVZ, Universidade Estadual Paulista - Unesp, Campus de Botucatu - SP, CP 560, CEP 18618-000, Brasil, E-mail: rafaelsbp@gmail.com

${ }^{*}$ A quem a correspondência deve ser enviada 
Segundo Rosa et al. (2006), o processo de cocção da carne altera os teores de proteína, gordura, cinzas e matéria seca devido à perda de nutrientes e água durante o processo; entretanto, a literatura a respeito das alterações ocorridas com alimentos durante a cocção é escassa.

Atualmente existe uma tendência quanto à redução da quantidade de calorias ingeridas diariamente pelas pessoas, principalmente as provenientes de lipídios, o que torna interessante conhecer a qualidade da carne in natura e a que passou por algum tratamento térmico, como cozimento, fritura, grelhada ou assada. A carne é considerada um alimento nobre para o homem, pois contribui, na dieta, com proteínas de alto valor biológico e outros nutrientes essenciais para a vida (PARDI, 1993).

A composição centesimal da carne sofre variações em função do tipo de músculo, da idade, da espécie animal, da nutrição, da raça, da condição sexual, do manejo pré-abate e pós-abate dos animais (FORREST, 1979). Os estudos com carne de cordeiros são, na maioria dos casos, relacionados aos fatores mencionados pelo autor supra citado, além de serem realizados com a carne in natura (ZAPATA et al., 2001; MADRUGA et al., 2002; ZEOLA, 2004), desconhecendo a composição química e a qualidade da carne que passa por algum tipo de processamento térmico, com finalidade do preparo do produto para o consumo.

Considerando a importância da nutrição e da saúde humana, justifica-se a necessidade de estudos avaliando a qualidade da carne, visando conhecer a composição centesimal do produto in natura e processado para o consumo. Diante do exposto, este trabalho tem por objetivos verificar a composição química e o rendimento da carne (in natura e assada) proveniente de cordeiros $1 \frac{1}{2}$ Ile de France $1 / 2$ Santa Inês, mais especificamente do corte da paleta oriunda da carcaça de ovinos não castrados.

\section{Material e métodos}

\subsection{Animais}

O experimento foi realizado utilizando-se o músculo Triceps brachii do corte da paleta de cordeiros não castrados $1 / 2$ Ile de France $1 / 2$ Santa Inês. Os animais foram terminados em regime de confinamento com alimentação ad libitum, constituída por $40 \%$ de silagem de milho e $60 \%$ de concentrado (grão de milho moído, farelo de trigo, farelo de soja, fosfato bicálcico, calcário calcítico, sal iodado, núcleo mineral e vitamínico). Quando os cordeiros atingiram aproximadamente $32 \mathrm{~kg}$ de peso corporal, os mesmos foram abatidos.

\subsection{Procedimento no pré-abate e no abate dos animais}

No pré-abate os cordeiros foram submetidos a jejum de 16 horas de dieta sólida. O abate foi efetuado, após insensibilização com eletronarcose, quando então foram seccionadas as veias jugulares e as artérias carótidas para sangria.

Após a esfola, evisceração e retirada da cabeça e extremidades dos membros, as carcaças foram transferidas para câmara frigorífica a $4^{\circ} \mathrm{C}$ por 24 horas. Ao final desse período, as carcaças foram divididas longitudinalmente em duas partes, sendo a metade esquerda seccionada em cinco regiões anatômicas, conforme Garcia (1998): paleta, pescoço, costelas, lombo e perna.

O pescoço compreendeu as $7^{\text {as }}$ vértebras cervicais, obtidas por corte oblíquo entre a sétima cervical e a primeira torácica; a paleta teve como base anatômica à escápula, o úmero, o rádio, a ulna e o carpo. As costelas compreenderam as $13^{\text {as }}$ vértebras torácicas, tendo-se efetuado um corte transversal na última vértebra torácica; o lombo correspondeu à região das vértebras lombares; a perna envolveu a base óssea do tarso, tíbia, fêmur, ísquio, ílio e púbis, seccionada na articulação da última vértebra lombar e primeira sacra e na junção tarso-metatarsiana.

A paleta da meia carcaça esquerda de cada animal foi identificada, armazenada em embalagens de polietileno e congelada em freezer a $-18^{\circ} \mathrm{C}$, para determinações posteriores da composição química da carne e da perda de peso após o seu preparo.

\subsection{Análises laboratoriais e determinação das perdas por cocção}

As paletas foram descongeladas em geladeira convencional à temperatura de $6{ }^{\circ} \mathrm{C} \mathrm{e}$, em seguida, as mesmas foram desossadas para retirada do músculo Triceps brachii (coração da paleta), sendo este desprovido de gordura de cobertura. Dos 16 músculos, 8 foram submetidos à análise química na carne in natura e os demais após serem assados. Antes das análises químicas, as carnes (músculo Triceps brachii) foram trituradas em multiprocessador para homogeneização e análises de umidade, proteína, gordura, cinzas e carboidratos.

A análise de proteína foi realizada pelo método Kjeldahl, em que o total de nitrogênio foi multiplicado pelo fator de conversão 6,25. O extrato etéreo foi determinado pelo método de Soxhlet. Por gravimetria foram determinadas: a umidade, utilizando-se uma estufa a $105^{\circ} \mathrm{C}$, e as cinzas, utilizando-se uma mufla com temperatura média de $600^{\circ} \mathrm{C}$, seguindo-se as recomendações da AOAC (1995). Os carboidratos foram calculados por diferença, onde foram subtraídos de 100 todos os valores obtidos das análises realizadas (SNIFFEN; O'CONNOR; VAN SOEST, 1992).

Para a determinação da perda de peso da carne assada, foi utilizado um forno a gás pré-aquecido à temperatura de $170^{\circ} \mathrm{C}$. As amostras de carnes cruas foram pesadas e colocadas em bandejas com grelhas de ferro. Em seguida, as amostras na grelha de ferro foram transferidas para o forno, onde permaneceram até a temperatura interna do centro da amostra atingir $75^{\circ} \mathrm{C}$. Após a referida etapa, as bandejas com as grelhas e amostras foram retiradas do forno e, quando esfriaram, as carnes foram pesadas novamente para o cálculo da percentagem de perda de água durante o cozimento. As perdas por gotejamento foram calculadas pesando-se a bandeja com grelha de ferro antes do preparo da carne e após a cocção da mesma. As perdas por evaporação foram calculadas através da perda por cocção menos a perda por gotejamento. Tanto as perdas por gotejamento, por evaporação ou por cocção foram determinadas em percentagem.

Todas as análises foram realizadas em triplicatas, no intuito de aumentar a confiabilidade dos resultados. 


\subsection{Delineamento experimental}

Foi utilizado o delineamento inteiramente casualizado, com dois tratamentos e oito repetições (16 parcelas experimentais). A análise de variância foi conduzida segundo procedimentos do programa estatístico Statistical Analysis System (SAS), versão 6.12 (1996), considerando-se o nível de significância de 5\%.

\section{Resultados e discussão}

Os valores médios da composição química: umidade, gordura, proteína, cinzas e carboidratos, avaliados na carne in natura e assada de cordeiros não castrados $1 / 2$ Ile de France $1 / 2$ Santa Inês, e os valores de desvio padrão, coeficiente de variação e valor de F, encontram-se na Tabela 1.

A umidade diferiu $(\mathrm{p}<0,01)$ entre os tratamentos estudados, com menor valor para a carne assada $(57,02 \%)$ em relação à carne in natura $(74,05 \%)$, fato justificado pela alta temperatura $\left(170{ }^{\circ} \mathrm{C}\right)$ durante o preparo da carne, que causou perdas por cocção de 35,20\%. Zeola et al. (2004) ao trabalharem com cordeiros confinados que foram alimentados com uma relação concentrado:volumoso de 60:40, obtiveram valores de umidade para a carne in natura destes animais de $75,75 \%$, valores próximos ao percentual de umidade para carne in natura dos animais deste estudo que também receberam a mesma relação de concentrado e volumoso e que também foram terminados em confinamento.

Macedo-Veiga et al. (2002) ao avaliarem a qualidade da carne de trutas arco-íris, observaram diminuição de umidade para carne pré-cozida em relação à in natura, como observado também por Badiani et al. (2002), Vieira (2007) e por este estudo, que o aumento da matéria seca ocorreu para a carne que passou por tratamento térmico (Tabela 1).

A forma de apresentação da carne (in natura e assada) teve efeito na composição centesimal da mesma. A carne assada apresentou maiores $(\mathrm{p}<0,01)$ teores de gordura $(7,49 \%)$ e proteína $(33,67 \%)$ que a carne in natura $(5,36$ e $18,85 \%)$. O ocorrido foi devido à perda de umidade da carne assada em relação à in natura, valor este, expresso em percentagem. A carne assada apresentou também, após o ato de assar, valores de gordura e de proteína maiores em relação à in natura, estando de acordo com Badiani et al. (1998), que relataram maiores valores de gordura na carne de cordeiros, após o cozimento da mesma. Quanto à proteína, Gall et al. (1983) e Farfán e Sammán (2003) também relataram maior percentual de proteína na carne que passou por algum tratamento térmico em relação à carne in natura, concordando com o ocorrido neste trabalho (Tabela 1).

Os valores de cinzas e carboidratos não foram influenciados $(\mathrm{p}>0,05)$ quanto à carne in natura ou assada, com valores médios de 1,18 e $0,60 \%$, respectivamente. Estes valores estão de acordo com Prata (1999), que relatou percentuais de cinzas de $1,1 \%$ e de carboidratos sendo menores que $1 \%$ para carne ovina. Souza et al. (2002) observaram que o valor de cinzas foi de $1,17 \%$ na carne de cordeiros abatidos com peso corporal de 15 a $45 \mathrm{~kg}$, semelhante ao valor obtido pelos cordeiros neste estudo (Tabela 1).
Tabela 1. Valores médios da composição centesimal da carne in natura e assada, proveniente de cordeiros e os respectivos desvios padrão, coeficiente de variação $(\mathrm{CV})$ e valor de $\mathrm{F}$.

\begin{tabular}{lrrrr}
\hline Variável (\%) & $\begin{array}{c}\text { Carne in } \\
\text { natura }\end{array}$ & Carne assada & Valor de F & CV (\%) \\
\hline Umidade & $74,05 \pm 1,05^{\mathrm{a}}$ & $57,02 \pm 1,34^{\mathrm{b}}$ & $796,64^{\star *}$ & 1,84 \\
Gordura & $5,36 \pm 1,02^{\mathrm{b}}$ & $7,49 \pm 1,32^{\mathrm{a}}$ & $11,79^{\star *}$ & 18,33 \\
Proteína & $18,85 \pm 0,50^{\mathrm{b}}$ & $33,67 \pm 0,78^{\mathrm{a}}$ & $716,25^{\star *}$ & 4,21 \\
Cinzas & $1,15 \pm 0,04$ & $1,21 \pm 0,13$ & $716,25^{\mathrm{Ns}}$ & 8,38 \\
Carboidratos & $0,59 \pm 0,0,15$ & $0,62 \pm 0,21$ & $0,02^{\mathrm{NS}}$ & 12,69 \\
\hline
\end{tabular}

${ }^{\mathrm{a}, \mathrm{b}}$ Letras distintas na mesma linha diferem significativamente entre si pelo teste de Tukey a $5 \%$ de probabilidade; NS = não significativo $(\mathrm{p}>0,05) ; \mathrm{e}^{* *}=$ significativo $(\mathrm{p}<0,01)$.

Tabela 2. Valores médios das perdas de peso por gotejamento, por evaporação e total da carne assada de ovinos e respectivos desvios padrão e coeficiente de variação $(\mathrm{CV})$.

\begin{tabular}{lcc}
\hline \multicolumn{1}{c}{ Variável (\%) } & Carne assada & CV (\%) \\
\hline Perdas por gotejamento & $1,36 \pm 0,28$ & 19,86 \\
Perdas por evaporação & $33,84 \pm 0,91$ & 2,88 \\
Perdas por cocção & $35,20 \pm 0,74$ & 2,25 \\
\hline
\end{tabular}

Na Tabela 2 são apresentados os percentuais de perdas por gotejamento, por evaporação e por cocção da carne.

As perdas por evaporação e por cocção da carne foram de 33,84 e 35,20\%, respectivamente. Bressan et al. (2001), ao trabalharem com cordeiros das raças Santa Inês e Bergamácia, obtiveram perdas por cocção de $28 \%$ no músculo Longissimus dorsi, sendo estas inferiores às deste estudo, sendo que essa diferença pode ter sido causada pelos diferentes tipos de músculos estudados.

A perda por gotejamento da carne assada foi de 1,36\%, pois esta carne estava desprovida de gordura subcutânea, apresentando então, gordura intermuscular e intramuscular. Abularach et al. (1998) ao estudarem as características de qualidade do músculo Longissimus dorsi de touros jovens da raça Nelore, obtiveram perdas por gotejamento de $4,87 \%$, superiores ao resultado deste estudo (Tabela 2 ).

\section{Conclusões}

O preparo da carne ovina para consumo (carne assada) não afetou os valores de cinzas e de carboidratos em relação aos valores da carne in natura.

O processo térmico utilizado para assar a carne ovina elevou o percentual de matéria seca da mesma, apresentando assim, teores lipídicos e protéicos mais elevados na carne assada quando comparada com a carne in natura.

O preparo da carne dos cordeiros para consumo causou perdas por cocção de $35,20 \%$, sendo $33,84 \%$ por evaporação e o restante por gotejamento.

\section{Referências bibliográficas}

ABULARACH, M. L. S; ROCHA, C. E.; FELÍCIO, P. E. Características de qualidade do contrafilé (m. $l$. dorsi) de touros jovens da raça 
nelore. Revista Ciência e Tecnologia dos Alimentos, v. 18, n. 2, p. 205-210, 1998.

AOAC - Association of Official Analytical Chemists. Official methods of analyses chemists. $16 \mathrm{ed}$. Arlington, 1995.

BADIANI, A. et al. Nutrient content and retention in selected roasted cuts from 3-month-old ram lambs. Food Chemistry, v. 61, n. 1, p. 89-100, 1998.

BADIANI, A. et al. Lipid composition, retention and oxidation in fresh and completely trim med beef muscles as affected by common culinary practices. Meat Science, v. 60, n. 2, p. 169-186, 2002.

BRESSAN, M. C. et al. Efeito do peso ao abate de cordeiros Santa Inês e Bergamácia sobre as características físico-químicas da carne. Revista Ciência e Tecnologia de Alimentos, v. 21, n. 3, p. 293-303, 2001.

FARFÁN, N. B.; SAMMÁN, N. Retention of nutrients in processed cuts of Creole cattle. Journal of Food Composition and Analysis, v. 16, n. 4, p. 459-468, 2003.

FORREST, J. C. et al. Fundamentos de ciencia de la carne. 1 ed. Zaragoza: Acribia, 1979.

GALL, K. L. et al. Effects of four cooking methods on the proximate, mineral and fatty acid composition of fish fillets. Journal of Food Science, v. 48, n. 4, p. 1068-1074, 1983.

GARCIA, C. A. Avaliação do resíduo de panificação "biscoito" na alimentação de ovinos e nas características quantitativas e qualitativas da carcaça. Jaboticabal, 1998. 79 p. Dissertação - (Mestrado em Zootecnia), Faculdade de Ciências Agrárias e Veterinárias, Universidade Estadual Paulista - Unesp.

GARCIA-ARIAS, M. T. et al. Cooking-freezing-reheating (CFR) of sardine (Sardina pilchardus) fillets: efect of different cooking and reheating procedures on the proximate and fatty acid compositions. Food Chemistry, v. 83, n. 3, p. 349-356, 2003.

MACEDO-VEIGA, E. M. et al. Rendimento e composição centesimal de filés in natura e pré-cozido em truta arco-íris, Oncorhynchus mykiss (Wallbaum). Revista Acta Scientiarum, v. 24, n. 4, p. 1191-1195, 2002.
MADRUGA, M. S. et al. Influência da idade de abate e da castração nas qualidades físico-químicas, sensoriais e aromáticas da carne caprina. Revista Brasileira de Zootecnia, v. 31, n. 3, p. 1562-1570, 2002.

PARDI, M. C. et al. Ciência, higiene e tecnologia da carne: tecnologia da sua obtenção e transformação. 1 ed. Goiânia: Universidade de Goiás, 1993.

PRATA, L. F. Higiene e inspeção de carnes, pescado e derivados. 1 ed. Jaboticabal: Funep, 1999.

ROSA, F. C. et al. Efeito de métodos de cocção sobre a composição química e colesterol em peito e coxa de frangos de corte. Revista Ciência Agrotécnica, v. 30, n. 4, p. 707-714, 2006.

SAS INSTITUTE. User's Guide to Statistics. Version 6.12. Cary, USA North Caroline State University, 1996.

SILVA, M. L. Efeito de dois métodos de cocção - água e vapor - nos parâmetros de qualidade do músculo Semitendinosus. Piracicaba, 2004. 114 p. Dissertação - (Mestrado em Ciências), Escola Superior de Agricultura 'Luiz de Queiroz", Universidade de São Paulo - USP.

SNIFFEN, C. J.; O'CONNOR, J. D.; VAN SOEST, P. J. A net carbohydrate and protein system for evaluating cattle diets: II. Carbohydrate and protein availability. Journal of Animal Science, v. 70, n. 11, p. 3562-3577, 1992.

SOUZA, X. R. et al. Composição centesimal do músculo Biceps femoris de cordeiros em crescimento. Revista Ciência Agrotécnica, edição especial, p. 1507-1513, 2002.

VIEIRA, J. O. et al. Efeito dos métodos de cocção na composição centesimal e colesterol do peito de frangos de diferentes linhagens. Revista Ciência Agrotécnica, v. 31, n. 1, p. 164-170, 2007.

ZAPATA, J. F. F. et al. Composição centesimal e lipídica da carne de ovinos do nordeste brasileiro. Ciência Rural, v. 31, n. 4, p. 691-695, 2001.

ZEOLA, N. M. B. L. et al. Composição centesimal da carne de cordeiros submetidos a dietas com diferentes teores de concentrado. Ciência Rural, v. 34, n. 1, p. 253-257, 2004. 